\title{
ILUSTRACIÓN Y RELIGIOSIDAD POPULAR: EL EXPEDIENTE DE COFRADÍAS EN LA PROVINCIA DE LEÓN (1770-1772)
}

\author{
Alfredo MARTíN GARCÍA \\ Universidad de León
}

\begin{abstract}
RESUMEN: El "Expediente General de Cofradías", mandado realizar por el conde de Aranda en 1770, muestra el notable dinamismo del mundo asociacionista seglar en la provincia de León durante el siglo XVIII. La labor pastoral de obispos y religiosos regulares en los siglos precedentes, propició su expansión, tanto por el mundo rural como por el urbano. En este trabajo se estudia el fenómeno desde un prisma territorial, social, económico y devocional.
\end{abstract}

PALABRAS CLAVE: León, cofradías, regalismo, mentalidades, religiosidad popular.

ABSTRACT: The "General Inquiry of Brotherhoods", ordered by count of Aranda in 1770, shows the important number of brotherhoods in the province of León in $18^{\text {th }}$ century. The pastoral work by bishops and friars in the previous centuries, favored its spreads in rural and urban areas. In this work we study this phenomenon in its aspects territorial, social, economic and devotional.

KEYWORDS: León, brotherhoods, mentalities, popular religiouness.

\section{LAS RELACIONES IGLESIA-ESTADO EN LA ESPAÑA DEL SIGLO XVIII}

Las cofradías constituían la forma asociativa más extendida en la España del Antiguo Régimen. Tras un período de crisis a comienzos de la Edad Moderna, fruto de las serias dificultades por las que pasaba la Iglesia, la reforma tridentina insufló a estas agrupaciones religiosas de seglares un nuevo aliento. La espiritualidad barroca caló tan profundamente en el universo devocional de las clases populares que el número de cofradías se disparó desde finales del siglo XVI en adelante. El proceso no se había decelerado, ni mucho menos, a mediados del 
XVIII, momento en el que superaban las 30.000 a nivel peninsular ${ }^{1}$. No parece pues descabellado considerar al fenómeno cofradiero como el principal cauce de la religiosidad popular y un elemento clave en la sociabilidad religiosa de la España del momento ${ }^{2}$.

Nuestro objetivo en este trabajo es calibrar el grado de importancia de este tipo de asociaciones en la provincia de León durante el siglo XVIII. Para tal fin contamos con una fuente de innegable valor: el Expediente de Cofradías elaborado, entre 1770 y 1772, por el intendente D. Juan Núñez del Nero ${ }^{3}$. Este extenso informe se redactó por orden del Consejo de Castilla, en el contexto del ambicioso programa de reforma del mundo asociacionista religioso que estaba abordando la Corona por aquellos años. Pese a que la fuente adolece de algunos defectos, ya constatados por otros autores ${ }^{4}$, su vaciado resulta de alto interés, pues nos ofrece una radiografia, bastante aproximada, del estado de salud del asociacionismo religioso seglar en la época. Antes de mostrar los resultados de su vaciado sistemático, parece a todas luces imprescindible contextualizar adecuadamente su proceso de gestación, para, de esta forma, comprender mejor su naturaleza y valorar en su justa medida la información que nos ofrece.

El Expediente de Cofradías es una manifestación más del secular pulso entre el trono y el altar, acentuado de manera considerable en tiempos de los Borbones. No hay duda alguna de que el sometimiento de la Iglesia era una de los factores esenciales para la consolidación del absolutismo. No existía otra institución que pudiera rivalizar con el Estado en influencia social, volumen burocrático, recursos económicos y capacidad intelectual para la disputa ${ }^{5}$. En buena parte de la Europa protestante esa cuestión se había solventado siglos atrás; tanto luteranos como anglicanos reconocían a sus monarcas como cabezas de sus estructuras

1 LóPEZ-GuAdaluPe MuÑoz, M.L. (1994). "Implantación de las cofradías en la diócesis de Granada durante la Edad Moderna". En. Congreso de Religiosidad popular en Andalucía. Córdoba: Ayuntamiento de Cabra. pp. 113-116.

2 LÓPEZ-GuAdalupe MuÑoz, M.L. (2001). "Religiosidad popular y jerarquías. Cofradías y sociedad en la España Moderna". En Ruiz Fernández, J. y Sánchez Ramos, V (coords.). La religiosidad popular y Almería. Almería: Instituto de Estudios Almerienses-Diputación de Almería. pp. 181-196, p. 182.

3 A.H.N. (Archivo Histórico Nacional), Leg. 7.095.

${ }^{4}$ Olano Pastor, M. (1999). "Las cofradías". En Rubio Pérez, L. (coord.). La Historia de León III. Edad Moderna. León: Universidad de León. pp. 470-475.

5 Álvarez SANTAló, L.C. (1999). “Control y razón: la religiosidad española del s. XVIII”. En Álvarez Santaló, L.C. y otros. Las cofradias de Sevilla en el siglo de las crisis. Sevilla: Universidad de Sevilla. pp. 7-34, p. 9. 
eclesiásticas. Sin embargo, en el orbe católico la situación era harto distinta, puesto que todas las iglesias nacionales debían obediencia al Sumo Pontífice. Así, si en aspectos de corte doctrinal los poderes temporales acataron sin muchos problemas las decisiones de Roma, en cuestiones disciplinares o de fuero mixto - matrimonios, educación, costumbres...-, las tensiones fueron el pan de cada día. Desde luego los problemas venían de lejos pero, sin duda, el siglo XVIII fue especialmente rico en conflictos de esta índole entre las principales potencias católicas y la Santa Sede ${ }^{6}$.

También en España las tensiones Iglesia-Estado se agudizaron en esa centuria. La Iglesia española resultaba un contrapeso inaceptable para el proceso de reforzamiento del poder monárquico que estaban acometiendo los diferentes gabinetes borbónicos. La Corona no sólo miraba con desconfianza la gran influencia del clero sobre la masa de fieles, sino que también era consciente de su potencial económico: cuanto menos, el $14,7 \%$ de la superficie cultivada del país estaba en sus manos, disfrutando del $24,1 \%$ del producto agrícola ${ }^{7}$. A este poder económico e ideológico y a su excesiva dependencia de Roma, harán frente los diferentes monarcas españoles desde los Reyes Católicos en adelante. Y es que el regalismo como tal no surge en el Siglo de las Luces, sino que constituye una línea de actuación que fue cobrando fuerza a lo largo de los años, a medida que el poder monárquico iba engrandeciéndose ${ }^{8}$. Los Borbones pues, se limitaron a tomar el relevo $-\mathrm{y}$ si se quiere agudizar- la política ejercida por sus antecesores. Las medidas aplicadas por la monarquía a lo largo de los siglos, no eran intrusiones ilegítimas del poder civil en la esfera eclesiástica, sino más bien una reacción al excesivo peso de Roma en ámbitos de competencia prioritariamente estatal ${ }^{9}$. El sueño de una Iglesia nacional no era, de todos modos, exclusivo de la Corona y sus ministros. Laicos sensibilizados, como Mayans ${ }^{10}$, o incluso un número no reducido

${ }^{6}$ Domínguez Ortiz, A. y Cortés PeÑA, A. L. (2006). “Cristianismo e Ilustración. Los inicios de la nueva era". En Cortés Peña, A.L. (coord.). Historia del cristianismo. III El Mundo Moderno. Granada: Universidad de Granada. pp. 831-874, p. 838 y ss.

7 Domínguez Ortiz, A. (1995). "Patrimonio y rentas de la Iglesia". En Artola, M. (dir.). Enciclopedia de Historia de España 3. Iglesia. Pensamiento. Cultura. pp. 75-138. p. 109.

8 LABOA, J.M. (1991). "La estructura eclesiástica durante la época moderna". En Llorca, B., García-Villoslada, R. y Laboa, J.M. Historia de la Iglesia Católica IV. Edad Moderna. La época del absolutismo monárquico (1648-1814). Madrid: Biblioteca de Autores Cristianos. pp. 193-259, p. 216.

9 EgIDO, T. (1979). "El regalismo y las relaciones Iglesia-Estado en el siglo XVIII". En García Villoslada, R. (ed.). Historia de la Iglesia en España IV. La Iglesia en la España de los siglos XVII y XVIII. Madrid: Biblioteca de Autores Cristianos. pp.124-161, p. 125.

${ }^{10}$ Vid. Mestre, A. (1968). Ilustración y reforma de la Iglesia. Pensamiento político-religioso de D. Antonio Mayáns y Síscar. 1699-1781. Oliva: Ayuntamiento de Oliva. 
de obispos, apostaban por esa vía. El objetivo de acabar de una vez por todas con la excesiva influencia de la curia romana en la Iglesia española, era compartido por todos; sin embargo, la divergencia era evidente en cuanto a los móviles y a los fines últimos que se trataban de alcanzar ${ }^{11}$.

Durante los reinados de Felipe V y Fernando VI se buscó alcanzar la vieja aspiración de lograr un acuerdo que permitiese satisfacer las ambiciones de la Corona. Tras algunos intentos fallidos, el concordato de 1753 supuso un paso adelante para el regalismo hispano, al ampliar el derecho de patronato al conjunto de sus dominios, amén de arrogarle la facultad de nombrar cerca de 50.000 beneficios. Ese importante éxito no sació las ambiciones de la Corona. En el reinado de Carlos III las presiones a la Iglesia se acrecentaron a través de la adopción de una serie de medidas cada vez más agresivas, comenzando por la expulsión de los jesuitas y continuando con las disposiciones tomadas para reducir el número de clérigos o para limitar el poder jurisdiccional de los ordinarios.

\section{CAMPOMANES, ARANDA Y EL EXPEDIENTE DE COFRADÍAS}

El despotismo ilustrado intentó también "racionalizar" y purificar la religiosidad popular, alejándola de sus ropajes barrocos, considerados por la minoría rectora del país como una indeseable manifestación de superstición y superchería. En esa línea, las cofradías, como principal cauce de aquella religiosidad, se podían convertir en un estorbo para la tan ansiada reforma de las costumbres pretendida por los ilustrados ${ }^{12}$. Las cofradías representaban, desde esa óptica, un arcaico vestigio de la estructura eclesiástica, reteniendo bienes y rentas destinados a funciones religiosas no siempre celebradas y dirimiendo conflictos al margen del control de los tribunales reales ${ }^{13}$.

${ }^{11}$ EGIDO, T. (1988). "La religiosidad de los ilustrados". En Jover Zamora, J. (dir.). Historia de España. XXXI. La época de la Ilustración. El Estado y la cultura (1759-1808). Madrid: Espasa-Calpe. pp. 397-435, p. 409.

12 Fueron muchos los autores de la segunda mitad del siglo XVIII que atacaron en sus escritos a las cofradías. Eugenio Larruga denunciaba que sus fondos se destinaban "mucho más en cuidar refrescos y otros inútiles y viciosos, que en el culto que tributan a los santos tutelares". Por su parte, Gaspar Melchor de Jovellanos señalaba que su "excesiva multiplicación, en lugar de mejorar, ha desfigurado el culto a que principalmente se dirige". Vid. LARRUGA Y BONETA, E. (1785-1800). Memorias politicas y económicas sobre frutos, comercio, fábricas y minas de España. (45 vols.) Madrid: Benito Cano. T. XXV. pp. 172 y ss.; A.H.N., Consejos, Leg. 827: Dictamen de Jovellanos al Consejo de Castilla en el expediente de la Congregación de $N^{a}$. Sra. de la Purificación (1789).

13 Mantecón Movellán, T. (1990). Contrarreforma y religiosidad popular en Cantabria. Santander: Universidad de Cantabria. p. 177. 
Las razones de orden moral y religioso no eran pues las únicas esgrimidas por los ilustrados para solicitar la intervención estatal en este campo. A la deficiente formación religiosa de las clases populares se añadían motivaciones de corte económico. Con la reforma, por un lado, se pretendía limitar la fuerza de los gremios, auténtico escollo para los planes de desarrollo industrial auspiciados por la Corona. Por otro, se buscaba acabar con el lastre que, desde su perspectiva, significaban para las endebles economías de las clases bajas las exigencias económicas de las cofradías ${ }^{14}$. El interés de la Corona por sujetar el exceso de gastos y actividades lúdicas de estas asociaciones venía ya de antiguo; tanto Enrique IV como el emperador Carlos llevaron adelante medidas en este sentido, aunque con muy discretos resultados ${ }^{15}$. En el reinado de Carlos III la Corona retomará esa tendencia, tratando de arrebatar las cofradías al control de los obispos y del clero regular.

Las primeras intervenciones del poder real sobre el asociacionismo seglar tuvieron lugar en la Villa y Corte, a partir de las discordias surgidas en 1762 en el seno de la hermandad de N ${ }^{\mathrm{a}}$. Sra. de la Natividad y San Antonio. Las disputas entre oficiales y maestros sastres fueron aprovechadas por el fiscal del Consejo de Castilla Pedro Rodríguez Campomanes para que aquel alto tribunal declarase el litigio como "auto de legos", alejándolo de la competencia del ordinario. Aunque el caso no tuvo consecuencias concretas, Campomanes concibió su informe como un ataque frontal a cofradías gremiales, solicitando su extinción. Cinco años después, lograría sus propósitos, aprovechando la solicitud de ordenanzas por parte de los mercaderes de hierro madrileños. El Consejo de Castilla aprobaba el 27 de julio de 1767 la supresión de todas las cofradías y hermandades gremiales y la recogida de sus ordenanzas ${ }^{16}$. No acabaron aquí las acciones contra cofradías y hermandades; en 1769, en el contexto del plan de reformas de los hospicios, los fiscales Campomanes y Moñino, abogaban en su informe por la supresión de las cofradías y la reorientación de sus cuantiosos bienes a estas instituciones asistenciales. No fue solamente la villa y corte el marco de acción de estas primeras medidas; en enero de 1770, el Capitán General de Cataluña enviaba a Madrid una

${ }^{14}$ Un profundo análisis sobre las raíces de la agresión ilustrada contra las cofradías puede verse en, ROMERo SAMPER, M. (1998). Las cofradias en el Madrid del siglo XVIII. Madrid: Universidad Complutense. pp. 303-468.

15 Arias De SaAvedra, I. y LÓPez Muñoz, M. L. (1994). "El expediente general de cofradías (1769-1784). Propuestas para su estudio”. En Martínez Ruiz, E. y Suárez Grimón, V. (eds.). Iglesia y sociedad en el Antiguo Régimen. Las Palmas: Universidad de Las Palmas. Vol. I. pp. 31-40, p. 32.

${ }^{16}$ Rumeu De Armas, A. (1981). Historia de la previsión social en España. Barcelona: Ediciones “El Albir”, p. 396. (La primera edición de esta obra clásica apareció en Madrid en el año 1944). 
representación en la que se quejaba de la gran cantidad de cofradías existentes en aquel principado "con solo el decreto del ordinario eclesiástico sin la aprobación de los magistrados reales". El rey mandó entonces que la Audiencia encargase a todos los corregidores del principado la recogida de las ordenanzas de aquellas que no disponían de autorización regia, prohibiéndose sus reuniones y actos hasta lograr la aprobación del Consejo de Castilla ${ }^{17}$.

Los ataques y victorias parciales alcanzadas sobre todo en la capital, animaron a los ministros de Carlos III a planificar una política más ambiciosa, de ámbito estatal. La perfecta disculpa para inmiscuirse en ese mundo se la ofreció en 1768 el obispo de Ciudad Rodrigo, D. Cayetano Cuadrillero. En junio de ese año, el prelado demandaba el auxilio del poder real para frenar los excesos contrarios en todo "a la santa ley de Dios" y a las "repetidas sabias órdenes de Su majestad" que provocaban algunas cofradías de su diócesis. Muy poco después, el obispo de Córdoba denunciaría casos semejantes para la suya. Estas peticiones motivaron la apertura de un expediente en el Consejo de Castilla, solicitándose el informe del fiscal Campomanes. Éste inició raudo la ofensiva, calificando a las cofradías como "antiguallas supersticiosas" y dejando claro su firme voluntad de limitar considerablemente su número ${ }^{18}$.

Acto seguido, a comienzos de 1769, el Consejo encargaba a los metropolitanos un informe sobre el estado de las cofradías y hermandades y la posibilidad de actuar sobre ellas ${ }^{19}$. No todos los prelados atendieron los requerimientos del Consejo Real; los arzobispos de Santiago, Toledo y Valencia guardaron un significativo silencio. Entre los que sí contestaron, hubo opiniones diversas, desde las marcadamente en sintonía con las ideas defendidas por Campomanes, caso de los muy regalistas arzobispos de Burgos y Tarragona, hasta las más moderadas de los de Sevilla y Granada. Obviamente, dentro de esta diversidad, el Consejo valoró en mayor medida las opiniones de los prelados más combativos, en especial las del tarraconense, D. Juan Lario y Lancis, vehemente defensor de la reducción del número de las cofradías antiguas y de la estricta limitación de las de nueva fundación.

${ }^{17}$ Novísima Recopilación, Lib. I, Ley VI, Tít. II

${ }^{18}$ Rumeu De Armas, A. (1981). Historia de la previsión social...”, p. 402.

19 ABBAD, F. (1977). "La confrarie condamnee ou une spontaneite festive confisquee. Un autre aspect de L'Espagne a la fin de L'Ancien Regime". Melanges de la Casa de Velazquez, pp. 361-384, p. 367. 
Tras el informe de las altas dignidades de la Iglesia española, el Consejo pasó a reclamar sendos informes a los intendentes de la Corona de Castilla y a los corregidores de la de Aragón. El 28 de septiembre de 1770, su presidente, el conde de Aranda, enviaba una circular en la que les reclamaba "una noticia exacta de todas las hermandades, cofradías, congregaciones, gremios y cualquiera especie de gentes colegiados que celebren una o más fiestas en el año, ya con la función de iglesia, y con otros exteriores de gasto y profesión". Esta información había de proporcionársela a los intendentes castellanos los justicias y ayuntamientos de su provincia. Las autoridades locales debían de hacer información del número de cofradías que existía en su término, especificando las funciones que sostenían anualmente y el importe de las mismas. Asimismo, los justicias debían de distinguir aquellas que contaban con aprobación del Consejo de las que solamente tenían la del ordinario o de aquellas que no disponían de autorización alguna. Una vez recogida toda esta información, los intendentes elaborarían un resumen general del estado de las cofradías en su provincia, al que acompañaría un informe particular en el que debían mostrar su parecer al respecto. Como es lógico, los intendentes se limitaron, en general, a respaldar las impresiones de los ministros del rey, aunque en diferentes grados ${ }^{20}$.

El 9 de agosto de 1773, el Consejo todavía no había recibido la totalidad de los expedientes. A pesar de esta circunstancia, el conde de Aranda dirigía una representación a Carlos III animándole a intervenir decididamente en el asunto, aplicando una política de carácter general para todos sus dominios peninsulares. El memorial de Aranda era, más bien, un manifiesto de principios, dado que cuando lo elaboró ya sabía su cambio de destino desde la presidencia del Consejo a la embajada en París. Quizás por esa razón el conde se mostraba más combativo que nunca, criticando abiertamente los excesos económicos de las cofradías y motivados por su apego a la ostentación, acusándolas, incluso, de fomentar la vagancia. Aranda contraponía a esa religiosidad ignorante y gravosa para las clases populares, la articulada en torno a las parroquias. No obstante, no todas las cofradías se incluían dentro de su feroz crítica; las sacramentales con sede parroquial, las de carácter espiritual y las asistenciales gozaban de una mayor consideración. La incendiaria declaración del conde no logró, de todos modos, acelerar el proceso del expediente, que continuó su lento deambular por las covachuelas de palacio. Tras la recepción de nuevas informaciones, el contador del Consejo, D. Manuel de Navarro, elaboró un resumen general, contabilizando un

20 Arias De SaAvedra, I. y LÓPEz Muñoz, M. L. (2002). La represión de la religiosidad popular. Crítica y acción contra las cofradías en la España del siglo XVIII. Granada: Universidad de Granada, pp. 250-251, p. 302. 
total de 19.024 cofradías para la Corona de Castilla y 6.557 para Aragón, que hacían un total de 25.581, cuyos gastos anuales se estimaban en 11.687.861 reales. Las cifras, tanto de cofradías como de gastos, adolecían de innegables defectos, dadas las inevitables ocultaciones que existían. Pero aún así, resultaban ciertamente clarificadoras de la importancia del asociacionismo seglar en la época.

Tras la elaboración de los resúmenes, el expediente pasó a manos de D. Vicente Paino y Hurtado, procurador general interino del reino, quien con cierta celeridad lo evacuó, el 25 de noviembre de 1775, con la intención de que el Consejo comenzase el necesario plan de reformas. Paino, siguiendo la estela de Aranda, recomendaba la supresión de todas las cofradías gremiales, así como de aquellas cuya sede se hallase en templo propio o en convento de regulares. Veía, de igual modo, necesaria para las restantes la exigencia de la aprobación real. Tuvieron que pasar siete años para que los fiscales del Consejo elaborasen su dictamen. La causa de este freno tan notable en el proceso estuvo motivada, como apuntan Arias Saavedra y López Muñoz, tanto por la marcha de Aranda a París como por el interés de los ministros de ligar este asunto al incipiente desarrollo de la beneficencia pública, plasmada en la creación de las juntas de caridad ${ }^{21}$. El 18 de abril de 1783, Campomanes presentaba, por fin, ante el Consejo el anhelado informe de los fiscales. En él se incidía claramente en argumentos económicos para justificar las medidas a tomar. También se apostaba por separar del expediente general todo lo referente a Madrid, que había de ser tramitado en un expediente aparte. Seguidamente, se recomendaba la creación en todas las provincias de Juntas de Caridad, con el fin de comenzar el proceso de extinción de cofradías, aplicando los fondos incautados a obras asistenciales, preferentemente a la creación de montepíos. Por último, y tras la justificación legal de esas medidas, establecían una clasificación de las cofradías en cinco grandes grupos, atendiendo a sus características y estado legal, proponiendo para cada una de ellas un tipo de actuación.

En primer lugar, propugnaban la desaparición total de las cofradías gremiales y de aquellas otras que no contasen con aprobación civil ni eclesiástica. Por el contrario, las que habían obtenido el respaldo legal de ambas jurisdicciones serían respetadas, aunque debían acudir al Consejo de Castilla para aprobar nuevas ordenaciones, con lo que quedaban absolutamente supeditadas al control de la Corona. Aquellas otras que solamente contaban con la autorización del ordinario deberían ser de igual forma suprimidas, si bien se les otorgaba un breve plazo para

21 Arias De SaAvedra, I. y LÓPEZ MuÑoz, M. L. (2002). La represión de la religiosidad popular..., pp. 324-326. 
intentar formalizar su situación ante el Consejo. Por último, las cofradías sacramentales eran respetadas, atendiendo al "sagrado objeto de su instituto", procurando no obstante su traslación al templo parroquial en el caso de que contasen con otra $\operatorname{sede}^{22}$. Asimismo, se debería prohibir la fundación de nuevas cofradías sin el pertinente consentimiento de la Corona. El Consejo de Castilla se avino a las recomendaciones expuestas por sus fiscales, elevando su consulta al rey en junio de 1783, quedando definitivamente aprobado el 17 de marzo de $1784^{23}$.

A pesar de la resolución firme de la Corona, este ambicioso plan de reforma, como tantos otros del XVIII español, no se llevó adelante, al menos en los términos expuestos. El propio Campomanes aconsejó su mitigación ante el temor a una oleada de protestas populares. Recomendaba pues la ejecución de las medidas solamente sobre aquellas cofradías inmiscuidas en procesos judiciales, frenándose de este modo, una de las armas más frecuentemente empleadas por aquellas para hacer valer sus derechos. Con todo, no todo el proceso cayó en saco roto, convirtiéndose en una brecha abierta por la monarquía que años después procuraría ensanchar, como demuestran los procesos desamortizadores de tiempos de Godoy o de José Bonaparte ${ }^{24}$.

\section{LA REFORMA DE LAS COFRADÍAS EN LA PROVINCIA DE LEÓN}

El 6 de julio de 1772 el intendente de León, D. Juan Núñez del Nero, remitía al conde de Aranda el listado de cofradías y congregaciones, elaborado por las justicias de las ciudades, villas y lugares de su provincia. Igualmente, y en cumplimiento de las órdenes del presidente del Consejo de Castilla, con el listado adjuntaba sus opiniones particulares. Ciertamente, el intendente leonés no fue especialmente original, ni en su diagnóstico de la realidad provincial, ni en las medidas que aconsejaba adoptar. Su informe es muy breve, limitándose en la práctica a repetir, casi con puntos y comas, las impresiones ya conocidas del fiscal Campomanes o de Aranda.

Esa necesidad de agradar a los ministros del rey, seguramente influyó también en las soluciones planteadas, que pasaban por "la extinzión y abolizión de la mayor parte de cofradías, hermandades y congregaciones de dichos pueblos", al considerarlas perjudiciales, tanto desde el punto de vista económico como desde el

\footnotetext{
${ }^{22}$ Rumeu De Armas, A. (1981). Historia de la previsión social..., pp. 405-409.

${ }^{23}$ Novísima Recopilación, Lib. I, Ley VI, Tít. II.

24 Arias De SAAVEdra, I. y LÓPEZ MuÑoz, M. L. (2002). La represión de la religiosidad popular..., p. 329.
} 
religioso. Solamente habían de conservarse las cofradías del Santísimo Sacramento y Ánimas que existían en las iglesias parroquiales, vigilando que se celebrasen en ellas las funciones correspondientes, con la debida decencia. Una decencia que no debía confundirse con "la pompa y banidad de los maiordomos y abades que por sobresalir acostumbran hazer inútiles y crecidos gastos, atrasándose en perjuicio de sus casas y familias" ${ }^{25}$. Para evitar esos notables quebrantos económicos, el intendente proponía que tanto el párroco como la justicia ordinaria de cada pueblo, supervisaran sus cuentas y los sistemas de elección de abades y mayordomos.

De mayor enjundia, tanto por su extensión como por las medidas que proponía, era el informe elaborado por el regimiento de León, posiblemente a petición del propio intendente. En el documento, fechado el 22 de febrero de 1772, los regidores leoneses reconocían que las obligaciones económicas a las que tenían que hacer frente los mayordomos y abades de las cofradías del entorno no eran de mucha entidad. Sin embargo, y a pesar de esta circunstancia, la pobreza del país hacía que hasta aquellas leves cargas pudiesen convertirse en pesados tributos para las frágiles economías de las clases populares. A estos inconvenientes se unía también que el ejercicio de esos puestos de responsabilidad en estas asociaciones, alejaba a los hombres "del cuidado de sus oficios, casa y familia". Se trataba, como vemos, de dos de los principales argumentos esgrimidos desde la Corte para llevar adelante la reforma del mundo asociacionista religioso. Nada hay, pues, de original en ese diagnóstico, como tampoco lo había en el firmado por el intendente.

Sin embargo, el consistorio leonés no se limitaba a repetir las directrices impuestas por los ministros del rey; iba más allá. Aprovechando la ausencia absoluta de cofradías con aprobación real, proponía un profundo programa de reformas. Para tal fin comenzaba dividiéndolas en tres categorías. La primera incluía a aquellas congregaciones en las que participaban activamente "las personas más principales de la ciudad". La segunda, englobaba a aquellas otras "que por instituto o costumbre" distribuían entre los cofrades "todo el resíduo de rentas", una vez satisfechas sus obligaciones económicas. Por último, en la tercera categoría quedaban integradas las que reinvertían sus beneficios en la propia institución; en este último grupo se incluía a las mayordomías de fábrica. Se trataba de una división de corte económico - marcada por el fin que le daba la cofradía a sus ingresos- pero sin que sus autores -regidores, y por ende integrantes de las elites- perdiesen la perspectiva estamental.

25 A.H.N., Consejos, Leg. 7.095. 
Atendiendo a esa última premisa, consideraban de utilidad la conservación de las hermandades de primera clase, "por que se sirven por las personas principales del pueblo y son de poca monta sus gastos, sirviendo al mismo tiempo de distintivo a los que le merecen". Las indultadas serían, por un lado, la cofradía de hijosdalgo "que por estatuto o costumbre requiere que el que haia de ser admitido por cofrade sea persona calificada" y, por otro, la del Milagroso Pendón "que tiene igual concepto o maior". Del mismo modo, se defendía el mantenimiento de las cofradías de segunda clase, puesto que las exigencias económicas para sus abades y mayordomos resultaban poco gravosas y la distribución de bienes que se hacía entre sus integrantes, les servía de socorro.

Las del grupo restante deberían ser suprimidas, juzgándose su número como excesivo. De todos modos, el municipio abogaba por la conservación de algunas de ellas, dado su destacado papel en el mundo religioso y asistencial de la ciudad. Así sucedía, por ejemplo, con la cofradía de la Veracruz, sita en el convento de San Francisco. Su innegable protagonismo en las celebraciones de la Semana Santa de la ciudad la hacía especialmente valiosa. Además, se valoraba la tradición de que fuera un vecino de la ciudad, elegido anualmente, el destinado a servirla. Los regidores recomendaban, no obstante, integrar en esta cofradía a todas aquellas que tuvieran su sede en la iglesia conventual, con el fin de aligerar al abad de sus obligaciones pecuniarias.

El consistorio defendía también la conservación de la cofradía de Ánimas del Malvar. En este caso las razones se relacionaban, fundamentalmente, con su loable fin social, puesto que sus rentas se invertían en el entierro de los pobres y las mujeres del hospital de San Antonio Abad. A ese argumento de peso se añadía otro de corte religioso, puesto que la hermandad sostenía de sus fondos un número importante de oficios, con el fin de socorrer, a través de la oración, a aquellas almas que se hallaban purgando sus pecados. Por motivos igualmente religiosos, consideraban oportuno mantener el resto de cofradías de Ánimas de la ciudad, así como también las sacramentales; de hecho, ambas se hallaban, por lo general, unidas. Como en el caso de la Veracruz, se proponía para su mejor sostenimiento, la incorporación de los bienes de algunas de las cofradías desaparecidas, siempre en proporción a la riqueza de cada una de ellas. Finalmente, la del Rosario era también salvada del proceso de extinción "para escitar a los fieles a tan santa devoción y que logren el copioso tesoro de indulgencias concedidas por ella". Detrás de esas pías motivaciones se escondían, de nuevo, otras de tinte social, ya que los abades de aquella cofradía eran "personas de la primera distinción y de las maiores combeniencias", añadiéndose, además que el caudal que debían invertir durante su mandato era ínfimo. 
Un especial interés suscitaron en el informe las hermandades de clérigos existentes en la ciudad; las cofradías del Ciento, Santa María del Sábado "la rica", San Pedro y San Pablo, así como la de Nuestra Señora de la Consolación y San Roque, estaban destinadas en exclusiva para sacerdotes, hallándose compuestas cada una de ellas por el simbólico número de doce. Estas asociaciones fueron las más duramente criticadas por los regidores. Tanto la última como, sobre todo, la del Ciento, estaban integradas por sacerdotes forasteros, no sólo de la ciudad sino incluso de la diócesis. Por tal motivo, sus obligaciones en León las servían clérigos mercenarios que residían allí "sin más utilidad experitual ni temporal de los fieles que la asistencia del cumplimiento de misa para utilizarse de las copiosas rentas que tiene la cofradía". A esa situación verdaderamente inapropiada, se unía la circunstancia de no haber en la ciudad ni un sólo beneficio patrimonial del que pudiesen sustentarse sus vecinos clérigos. Por otra parte, resultaba también evidente la cortedad de las rentas parroquiales en las iglesias del casco.

Todos estos motivos animaron al consistorio a proponer que se agregasen las cuantiosas rentas de esas cuatro cofradías, junto con las de las restantes desaparecidas "a una masa común". Esos importantes fondos económicos gestionados por un mayordomo secular "para no distraer en esto a ningún eclesiástico"-, serían divididos en veinticuatro partes iguales. Dieciocho servirían para proveer otros tantos beneficios eclesiásticos que se resolverían, previo concurso y examen sinodal, entre "hijos patrimoniales naturales de esta ciudad". Los clérigos elegidos tendrían la obligación de cumplir con los encargos y misas de las cofradías agrupadas, además de dedicarse a labores de confesión y a ayudar a los párrocos a servir en sus respectivas parroquias. Incluso, en momentos excepcionales, podían ser destinados a otros lugares de la diócesis, siempre que el obispo lo considerara estrictamente necesario.

Las restantes seis partes se destinarían a los párrocos incongruos de la ciudad todos, a excepción del de San Martín-, atendiendo a su mérito y necesidad. Para tal fin, también en este caso, se llevaría adelante un "concurso y examen de suficiencia", con el objetivo de que "se esmeren más en el desempeño de su obligación y les sirva de premio". Las seis partes de los párrocos como las dieciocho de los beneficiados patrimoniales eran todas semejantes, tanto en el monto económico a percibir como en las obligaciones a desarrollar, no existiendo derecho alguno de entrada, ni gastos de comida ni de otro tipo.

Mucho más escueto y poco original era el apartado referido a las cofradías de los pueblos del entorno rural circundante. En él, consideraban los regidores leoneses, sería conveniente eliminarlas todas, puesto que, en su opinión, distraían a sus integrantes de la asistencia a sus casas y además de que los gastos de 
colaciones, comida y bebida, así como los escotes, se solían realizar al fiado o "haciendo otros tratos reprovados so color de piedad y de aumento de las cofradías". No descartamos la incidencia de esas obligaciones pecuniarias en las frágiles economías campesinas, aunque posiblemente se deben hacer importantes matizaciones. Sin embargo, la acusación vertida sobre la distracción de las haciendas que podía motivar el ingreso en una hermandad, parece, cuanto menos, improbable para el mundo rural ${ }^{26}$.

Esas son, a grandes rasgos, las grandes líneas argumentales de los informes del intendente y el consistorio leonés. Si el primero adolece de una evidente desgana a la hora de diagnosticar las irregularidades y abusos existentes en la provincia, el segundo, al menos, plantea problemas y alternativas, aunque desde una óptica profundamente conservadora: los bienes resultantes de la desaparición de cofradías habían de destinarse a la creación de nuevos beneficios eclesiásticos y no a medidas de corte social, como defendía Campomanes. Aún así, los argumentos generales que se enarbolan para justificar la reducción de cofradías son, tanto en uno como en otro, meros calcos de las opiniones de los promotores del proyecto. Por otro lado, en el caso del informe del municipio se dejan entrever los intereses de clase de unos regidores que no tenían el menor recato en defender sus propias instituciones religiosas como baluartes del orden social establecido. En esa misma sintonía podría situarse su vivo interés en la creación de esos nuevos beneficios eclesiásticos, vistos, quizás, como una apetecible salida profesional para sus segundones.

\section{EL ASOCIACIONISMO RELIGIOSO LEONÉS EN EL SIGLO XVIII: CARACTERÍSTICAS GENERALES}

Ya hemos señalado la importancia del Expediente de Cofradías por su valor fotográfico de la realidad asociacionista leonesa en el último tercio del siglo XVIII. Sin embargo, y a pesar de sus innegables virtudes, la fuente adolece de algunos problemas que debemos señalar. En primer lugar, y pese a que en ella se alude a la totalidad del territorio provincial leonés de la época, algunas comarcas quedan al margen del recuento (mapa 1$)^{27}$. Sin lugar a dudas, la ausencia más destacada es la del Bierzo, territorio que queda por completo fuera de esta relación. Aunque desconocemos a ciencia cierta la causa de esa importante carencia, parece probable

${ }^{26}$ Barreiro Mallón, B. (2002). "La diócesis de Santiago en la Época Moderna”. En García Oro J. (coord.). Historia de las diócesis españolas. Vol. XIV (Santiago de Compostela y Tuy-Vigo). Madrid: Biblioteca de autores cristianos. pp. 177-351. p. 317.

${ }^{27}$ Para facilitar nuestro análisis, hemos elaborado dos mapas sobre la base de los actuales límites municipales. Agradecemos a Raquel Martínez Peñín la ayuda prestada en su confección. 
apuntar bien un retraso en el envío de la información por parte de las autoridades de la zona, bien su pérdida en algún momento de la tramitación del expediente. Otras ausencias significativas son la de la ciudad de Astorga y la comarca de la Cabrera, quedando, además, algunos ámbitos territoriales muy puntuales al margen de la relación. El astorgano es, ciertamente, un caso especial, si tenemos en cuenta que contamos con la relación de todos los pueblos de su alfoz.

A pesar de estos defectos, el ámbito territorial que comprende la encuesta resulta lo suficientemente amplio como para que los resultados puedan ser considerados como altamente fiables: prácticamente las tres cuartas partes del actual marco provincial quedan englobadas en él. Estos inconvenientes, aunque apreciables, no llegan a los manifestados para otros ámbitos peninsulares ${ }^{28}$. Por otro lado, y en contrapartida a la ausencia de localidades leonesas, entre las 1.527 referencias localizadas aparecen 62 vinculadas a la actual provincia de Valladolid, 31 a Zamora y 2 a Asturias, consecuencia evidente de las diferencias territoriales entre la provincia de León en el Antiguo Régimen y la nacida tras las reformas liberales. Dado el restringido espacio con el que contamos en este trabajo, nos limitaremos simplemente a esbozar las principales características del asociacionismo religioso seglar leonés en la época, remitiéndonos a posteriores publicaciones para el desarrollo de un análisis de mayor profundidad.

Una primera cuestión a resolver es la del número de cofradías y su distribución espacial en la provincia leonesa en el siglo XVIII. Para tal fin hemos elaborado un mapa, reubicando los datos aportados por la fuente en el actual marco municipal (mapa 2). De su lectura podemos colegir, en primer lugar, el abrumador predominio del mundo rural sobre el urbano; solamente el 7,9\% de las 1.504 cofradías localizadas estaban ubicadas en un núcleo de población de cierta entidad $^{29}$. Esta circunstancia es consecuencia directa del proceso de

${ }^{28}$ En el reino de Galicia solamente aparecen mencionadas las cofradías de las siete capitales y en ellas ni siquiera todas. Deficiencias importantes se han hallado, asimismo, en el caso asturiano o burgalés. Sin embargo, los resultados parecen más razonables para la diócesis de Segovia. Vid. LÓPEZ, R.J. (1990). "Las cofradías gallegas en el Antiguo Régimen". Obradoiro de Historia Moderna. Homenaje al profesor Antonio Eiras Roel en el XXV aniversario de su cátedra. Santiago: Universidad de Santiago. pp. 181-200. p. 181; CARASA SotO, P. (1983) "La asistencia social y las cofradías en Burgos desde la crisis del Antiguo Régimen". Investigaciones Históricas. pp. 117-230. pp. 185-186; LóPEZ, R.J. (1989). Comportamientos religiosos en Asturias durante el Antiguo Régimen. Gijón: Biblioteca Histórica Asturiana. p. 186; BARRIo GozAlo, M. (1997). "Las cofradías en la diócesis de Segovia en el siglo XVIII". Religiosidad popular en España. Actas del simposium. Edes: Madrid. pp. 217-234.

${ }^{29}$ En ese porcentaje hemos incluido las cofradías de la ciudad de León, junto con las de las villas de Sahagún, La Bañeza y Valderas. 
adoctrinamiento llevado adelante por la Iglesia tras el Concilio de Trento. Hasta entonces, estas asociaciones religiosas prácticamente no habían logrado ir más allá del ámbito urbano o semiurbano -las villas- siendo, en gran medida, fruto más que de cuestiones meramente religiosas de necesidades de tipo socio-asistencial o lúdico. Por el contrario el fenómeno asociacionista a partir de Trento se convirtió en un eficaz vehículo de propaganda y adoctrinamiento, aprovechado y fomentado por la propia Iglesia ${ }^{30}$. Ese movimiento instigado desde arriba es el que explica su desarrollo y extensión por la práctica totalidad del territorio leonés. La dispersión y la concentración en el área rural son las dos primeras conclusiones que debemos sacar. Cierto es, no obstante, que en el mundo urbano, el número de cofradías superaba claramente la media; así en la capital del reino, existían para el año 1772 un total de 66. Un número ciertamente importante si tenemos en cuenta que, por aquellas mismas fechas, Santiago de Compostela contaba con 53 y Oviedo solamente con $35^{31}$. Las diferencias son notables, máxime si tenemos en cuenta el menor peso demográfico de León con respecto a aquellas otras ciudades del Noroeste peninsular ${ }^{32}$. Por esa misma trayectoria caminaría posiblemente la ciudad de Astorga, aunque, como ya hemos señalado, la fuente no nos aporta información al respecto ${ }^{33}$. Igualmente, localidades de cierto peso demográfico en el contexto provincial, caso de La Bañeza, Sahagún de Campos o Valderas, mostraban también un apreciable dinamismo: la primera contaba con 17 cofradías, por 16 de la segunda y 12 de la tercera.

La preponderancia del mundo rural y la dispersión del fenómeno son, pues, dos de los aspectos más significativos del asociacionismo seglar leonés. La visualización del mapa nos muestra, por otro lado, cómo la zona de mayor densidad de cofradías se concentraban en una lengua territorial que partiendo desde León avanzaba hacia el suroeste de la capital. Esa amplia zona que englobaría, a grandes rasgos, el alfoz leonés, el Páramo y la comarca bañezana aportaba el

${ }^{30}$ BARReiro Mallón, B. (2002). “La diócesis de Santiago...”. pp. 305-306.

${ }^{31}$ LÓPEZ, R.J. (1990). “Las cofradías gallegas...”. p. 181; LÓPEZ, R.J. (1985). Oviedo: muerte y religiosidad en el siglo XVIII (un estudio de mentalidades colectivas). Oviedo: Comunidad Autónoma del Principado de Asturias. pp. 156-157.

32 Mientras que en 1787 León contaba solamente con 6.051 habitantes, Oviedo tenía 13.550 y Santiago alcanzaba los 17.323; (1990). Censo de 1787 "Floridablanca". Madrid: Instituto Nacional de Estadística. Vol. 4 (Comunidades Autónomas del Norte Atlántico). pp. 3.576 y 3.775; Vol. 3B (Comunidades de la Submeseta Norte). p. 3.062.

${ }^{33}$ Gregoria Cavero, en su ya clásica obra sobre las cofradías astorganas durante la Edad Media, nos muestra con meridiana claridad su dinamismo durante aquella época. Vid. CAVERo DomínGUEZ, G. (1992). Las cofradias en Astorga durante la Edad Media. León: Universidad de León. pp. 69-73. 
$45,7 \%$ del total. Junto a esa importante área, resulta especialmente significativo el papel desempeñado por las cofradías en la Montaña leonesa en general y en su zona occidental en particular ${ }^{34}$. Los actuales municipios de Murias de Paredes, Barrios de Luna y, por encima de todos, Riello, concentraban un número más que considerable de cofradías; en concreto 113. Ciertamente esa fuerza numérica debe quedar un tanto diluida en la importante extensión territorial de esos municipios ${ }^{35}$ pero, aún así, parece evidenciar un importante movimiento pastoral en la zona, promovido tanto por las autoridades diocesanas -en la mayoría de estos pueblos las ovetenses- como por las órdenes religiosas. Parece pues descartarse, al menos para el siglo XVIII, la imagen de una montaña poco influida por la religiosidad reformista. De todos modos, es probable que su integración en esa dinámica espiritual fuera más tardía que en otras zonas mejor comunicadas ${ }^{36}$.

Otro aspecto de singular importancia es dilucidar la tipología de las cofradías leonesas, atendiendo a sus devociones y advocaciones. Aunque este aspecto ya ha sido tratado en otros trabajos ${ }^{37}$, no podemos resistimos a efectuar una somera lectura de los datos obtenidos sobre el vaciado de las 1.519 cofradías que ofrecen dicha información (gráfico 1). Son aquellas cuyo titular era un santo las que más abundaban en el León del siglo XVIII; su peso es del 21,3\%, incrementado hasta el $24,7 \%$ si añadimos aquellas que tenían por titular a una santa. Entre la importante diversidad de patronos, destacan por encima de todos, los sanadores o protectores del ganado, caso de las figuras de San Roque, los santos mártires San Fabián y San Sebastián o San Antonio Abad. Muy poco por detrás de este importante grupo de cofradías, con un $21 \%$ del total, nos encontramos con las de la Cruz o la Veracruz el término varía dependiendo de las zonas-. La devoción a la cruz, de marcada influencia franciscana, procede de la Baja Edad Media y está estrechamente unida a la veneración de sus reliquias -el lugnum crucis- y a la celebración de los misterios de la Pasión de Cristo, a través de las procesiones y la disciplina. Por lo

${ }^{34}$ La Montaña occidental de León aporta el 14,5\% de las cofradías, porcentaje que sube al 27,4 si incluimos a los concejos de la Montaña central y oriental.

${ }^{35}$ El actual ayuntamiento de Riello cuenta nada menos que con 39 entidades poblaciones.

${ }^{36}$ Sirva como ejemplo que las ordenanzas de la cofradía del Santísimo Sacramento y Ánimas de Murias de Paredes se aprobaron en el año 1723. Vid. PÉrez Álvarez, Mà.J. (1997). "Las cofradías en la Montaña de León: canal de expresión del fervor popular”. Religiosidad popular... Vol I. pp. 4755. p. 48.

37 Olano Pastor, M. (1999). “Las cofradías...”. pp. 474-475. 
que parece, en el caso leonés, como también sucedía en la vecina Zamora ${ }^{38}$, estas cofradías no habían perdido su vigencia en pleno siglo XVIII. Por su parte, las marianas ocupaban el tercer lugar en cuanto a importancia, destacando sobremanera el papel desempeñado por la devoción a la Virgen del Rosario. La mitad de las 290 cofradías marianas contaba con esa advocación, datos coincidentes con otros ámbitos territoriales peninsulares ${ }^{39}$.

Por su parte, una devoción tan profundamente ligada a los ritos funerarios, como era la de las Ánimas del Purgatorio, contaba con un apreciable porcentaje de cofradías -el 17\% del total-. Mientras, las sacramentales no habían alcanzado un especial desarrollo, a pesar del vivo interés de las autoridades diocesanas por fomentar el culto al Santísimo. Es posible, con todo, que esos discretos resultados puedan entenderse, en parte, por la existencia de cofradías de otro título encargadas de mantener encendida la lámpara del sagrario. El resto de hermandades e institutos seglares jugaba ya un papel poco importante en el mundo religioso leonés del momento ${ }^{40}$.

La labor de control del asociacionismo seglar por parte de las autoridades diocesanas alcanzaba, en el siglo XVIII, unos niveles ciertamente altos. Solamente un $11,4 \%$ de las cofradías leonesas del momento no contaban con la pertinente autorización eclesiástica. El hecho de que el 97,6\% de ellas tuviesen su sede en el templo parroquial facilitaba en gran medida esa vigilancia. Muy poco frecuente era, por el contrario, la aprobación por parte de la Corona. Se trataba de casos muy puntuales, ligados casi exclusivamente al mundo urbano o semiurbano. Algunas cofradías, sin embargo, pretendían legitimar su existencia aludiendo a viejos privilegios reales concedidos en lejanas fechas. Así, la hermandad de la Veracruz de Sahagún, afirmaba contar con la aprobación del "señor rey D. Alonso el sexto".

${ }^{38}$ Vid. JARAmillo Guerreira, M.A. (1987). "Las cofradías de la Cruz en la diócesis de Zamora (siglo XVI)". I Congreso nacional de cofradias de Semana Santa. Zamora: Diputación Provincial de Zamora. pp. 217-230.

39 GonZÁLez LOPO, D.L. (1992). "La evolución del asociacionismo religioso gallego en la segunda mitad del siglo XVIII: el arzobispado de Santiago". En. Gremios, hermandades y cofradias. (Actas de los VII Encuentros de Historia y Arqueología). Vol. II. San Fernando: Ayuntamiento de San Fernando. pp. 27-42. p. 37.

${ }^{40}$ Dentro del epígrafe "Divinidad" englobamos a aquellas cofradías dedicadas al culto de Dios en sus múltiples manifestaciones: Santísima Trinidad, Dulce Nombre de Jesús, Espíritu Santo, etc. En rigor, las cofradías de la Veracruz también deberían estar incluidas en este grupo pero, dado su importante volumen, hemos optado por separarlas. Las "agrupadas" son aquellas resultantes de la unión de dos o más cofradías. Las terceras órdenes seglares -en especial la franciscana-, institutos seculares y cofradías de nobles y eclesiásticos, las hemos integrado en el genérico epígrafe "otras". 
La propia justicia de la localidad señalaba, no obstante, que la cofradía no contaba con instrumento alguno para sustentar tal afirmación, salvo las armas reales colocadas en su ermita.

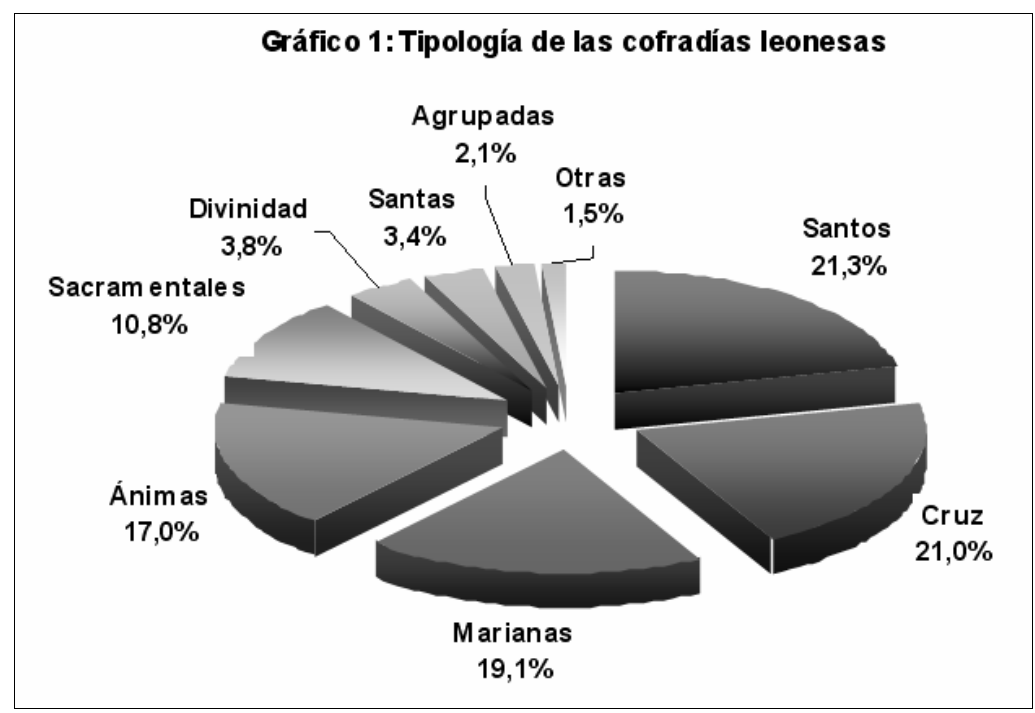

Finalmente, el expediente informaba también de la vida económica de las cofradías. Lógicamente, los resultados adolecen de una importante dosis de ocultación, al tratar los cofrades de esconder el verdadero patrimonio de su hermandad, ante el temor de la intervención estatal. De todos modos, y teniendo en cuenta que ese interés sería extrapolable a todas las relaciones efectuadas en el resto de España, el contraste de esos resultados con los de otras provincias nos puede ayudar a calibrar, en su justa medida, el peso económico de las cofradías leonesas. Una de las principales acusaciones vertidas contra estas asociaciones era la del excesivo gasto económico que suponía su mantenimiento, con la consiguiente repercusión en las endebles economías de las clases populares. Tales afirmaciones, a la luz de la documentación manejada, parecen más fáciles de sustentar para el caso andaluz o levantino que para las hermandades de la mitad norte peninsular. Así lo demostraba hace ya algunos años Tomás Mantecón en su estudio basado en los resultados generales ofrecidos por los distintos intendentes. En él incluía a León en el grupo de provincias con cofradías menos gastadoras, dentro de un área que englobaría desde Galicia a Navarra, pasando por Asturias, 
Burgos o las provincias vascas ${ }^{41}$. Aunque, a grandes rasgos, esas afirmaciones continúan plenamente vigentes, nuestros cálculos elevan un tanto su monto anual de gastos, situándolo en 346 reales, frente a los menos de 250 que indicaba aquel trabajo. Estos resultados se aproximan más los obtenidos para las vecinas provincias de Zamora y Palencia, quedando todavía lejos de los vallisoletanos. Es necesario recalcar, no obstante, que las estimaciones han de ser tomadas como una mera referencia. No podemos obviar que solamente el $14,1 \%$ de las cofradías catalogadas en la provincia ofrecen esta información; muestra evidente de su interés por ocultar su verdadero patrimonio.

En general, sus gastos se destinaban, en primer lugar, al culto y, en segundo, al sostenimiento de actividades lúdicas en torno a la festividad del patrón, comenzando por el inexcusable refresco o convite y continuando -dependiendo de los casos- por los bailes, fuegos, etc. Muy pocas eran las cofradías que desviaban parte de sus bienes a labores asistenciales: solamente el $0,7 \%$ de ellas reservaba una parte a la limosna de pobres y el 0,9\% desarrollaba labores hospitalarias. En cuanto a los ingresos, el $43,9 \%$ de las cofradías leonesas declaraban vivir exclusivamente de las caridades de sus miembros ${ }^{42}$. Generalmente éstas consistían en un escote anual, con el fin de sufragar las funciones del santo patrón. A ese importante porcentaje, habría que unir el de todas aquellas cofradías que, pese a contar con algún tipo de ingreso, necesitaban del aporte de sus integrantes para equilibrar sus cuentas anuales. En consecuencia, aquellas con un patrimonio suficiente eran muy minoritarias.

Aún así, la mayoría de ellas participaban, en mayor o en menor medida, de la propiedad de la tierra. La práctica común era su arriendo, obteniendo de esta forma mayores ingresos, aunque a veces se podía rozar la ilegalidad ${ }^{43}$. Este importante soporte económico sufrirá, como ya ha demostrado el profesor Rubio Pérez ${ }^{44}$, un

41 Mantecón Movellán, T. (1990). Contrarreforma y religiosidad popular... p. 185.

${ }^{42}$ Ya hemos señalado el carácter meramente orientativo de estos datos al hallarse influidos por el interés ocultador de los cofrades. Estas impresiones, por tanto, han de ser ratificadas a través de un estudio más profundo sobre la base, tanto de sus propios libros de cuentas como de los protocolos notariales.

${ }^{43}$ Las autoridades diocesanas de Astorga tuvieron que intervenir ante los abusos cometidos por sus cofradías a este respecto. RUBio PÉREZ, L. (1987). "Las cofradías leonesas durante la Edad Moderna: el ejemplo de la diócesis de Astorga". I Congreso nacional de cofradías... pp. 231-242. p. 235.

44 Vid. Rubio PéReZ, L. (1987). "Los bienes de las cofradías y su desamortización durante el reinado de Carlos IV: un primer proceso de centralización de la tierra en la diócesis de Astorga". Tierras de León. pp. 49-57. 
notable quebranto a raíz del proceso desamortizador desarrollado a finales de siglo. Junto a la tierra, eran también numerosas las cofradías que contaban con participación en la cabaña ganadera, tanto ovina como, sobre todo, bovina. Aún siendo importante su concurso en la Meseta, el peso del ganado vacuno en las zonas de montaña resultaba allí determinante, sustituyendo, en muchos casos por completo, a la propiedad de la tierra. El tercero de las fuentes de ingresos de las cofradías eran los censos, aprovechando la demanda de recursos tanto del campesinado como, incluso, de las clases dominantes ${ }^{45}$.

${ }^{45}$ RUBIO PÉREZ, L. (1987). “Las cofradías leonesas...”. p. 236. 


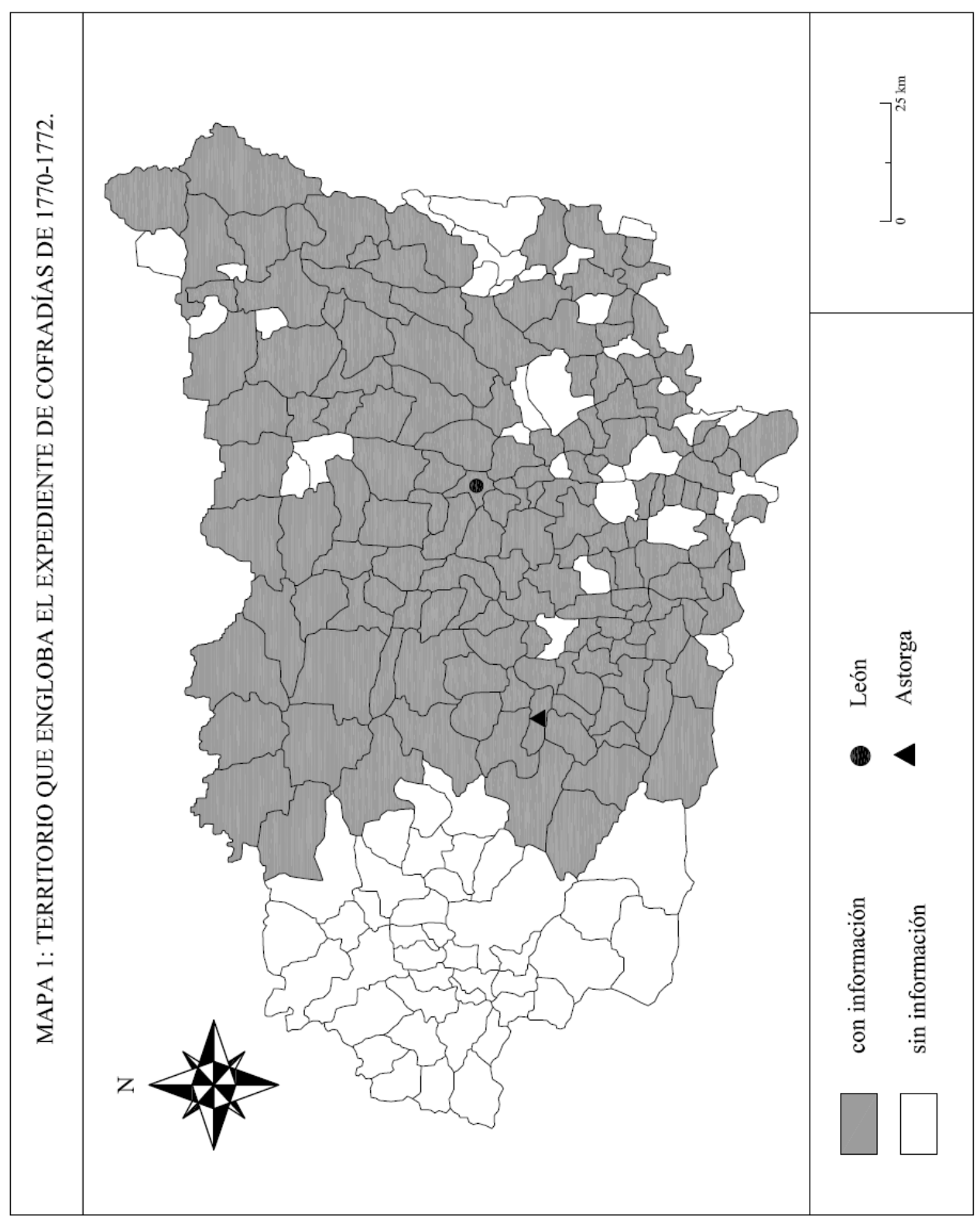




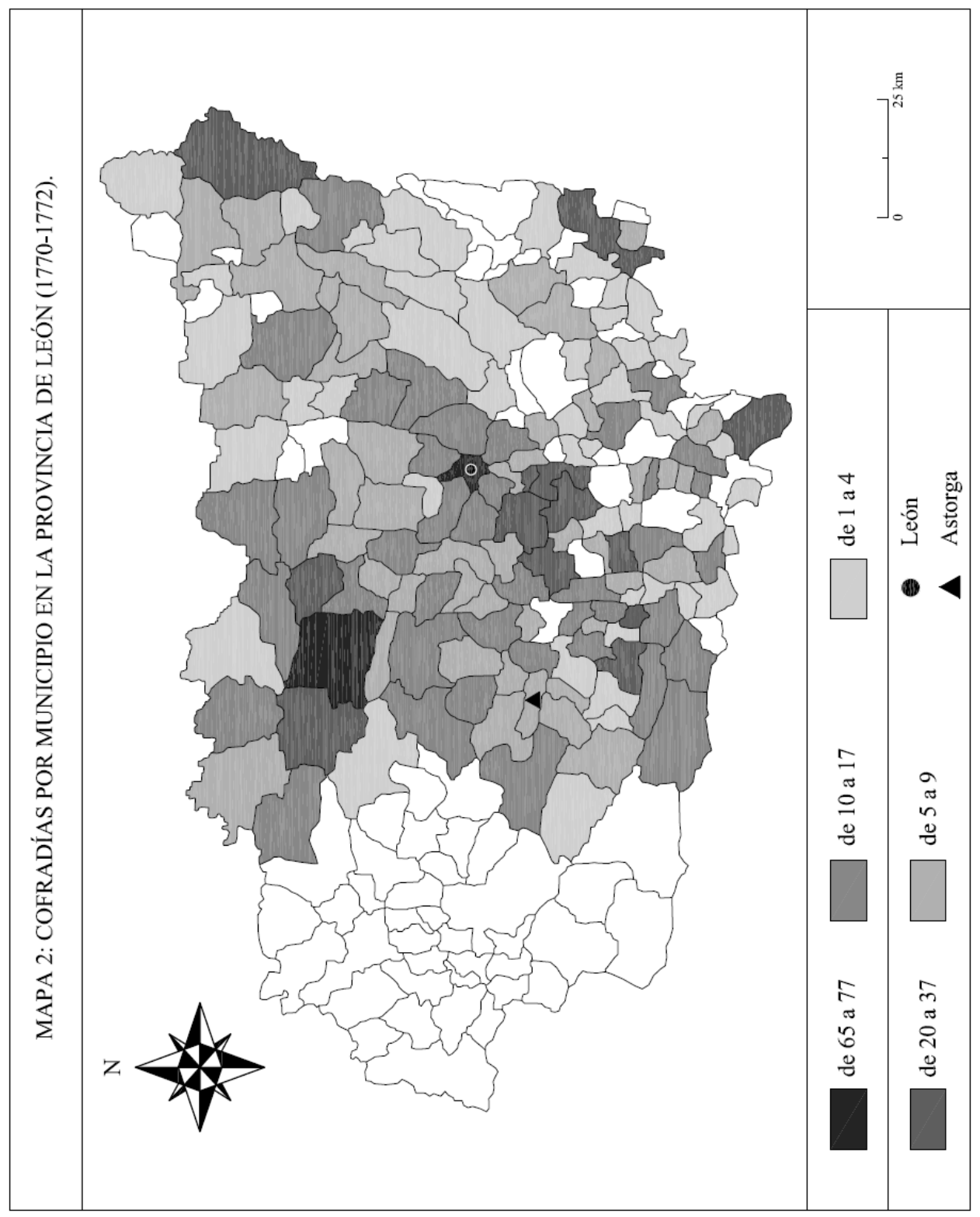

